\title{
PENGEMBANGAN PERKERASAN LENTUR PADA RUNWAY BANDAR UDARA NOTOHADINEGORO JEMBER
}

\author{
Eva Wahyu Triliah ${ }^{1}$, Koespiadi $^{2}$

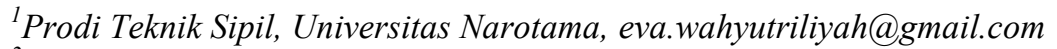 \\ ${ }^{2}$ Prodi Teknik Sipil, Universitas Narotama, koespiadi@narotama.ac.id
}

\begin{abstract}
ABSTRAK
Indonesia merupakan Negara kepulauan yang memiliki sebanyak 237 bandara sebagai salah satu akses penghubung dari kota ke kota. Di Kabupaten Jember sendiri memiliki bandara perintis yang hanya mempunyai panjang landasan pacu (runway) sepanjang $1.645 \mathrm{~m}$ dan hanya mampu didarati oleh pesawat kecil berjenis ATR 72 sehingga kurang memadai untuk akses dari kota menuju Kabupaten Jember. Oleh sebab itu Bandar Udara Notohadinegoro Jember perlu dilakukan perpanjangan pada landasan pacu (runway) agar mampu didarati pesawat berbadan besar sesuai pesawat rencana Boeing 747 -400ER.

Berdasarkan hasil analisa perhitungan menggunakan metode FAA (Federal Aviation Administration)di dapatkan hasil dimensi perkerasan lentur untuk pesawat rencana Boeing 747 - 400 ER untuk 20 tahun yang akan datang panjang runway $3.300 \mathrm{~m}$ dan lebar $45 \mathrm{~m}$ dimana sebelumnya landasan pacu (runway) eksisting hanya $1.645 \mathrm{~m}$ dan lebar $30 \mathrm{~m}$. Dan total tebal perkerasan adalah $99 \mathrm{~cm}$, dengan subbase $56 \mathrm{~cm}$, base course $30 \mathrm{~cm}$ dan surface $13 \mathrm{~cm}$.
\end{abstract}

Kata Kunci : Perkerasan lentur, runway, FAA

\section{PENDAHULUAN}

Bandara adalah salah satu faktor yang mempengaruhi pertumbuhan perekonomian suatu daerah, karena memudahkan akses untuk moda transportasi maupun keperluan logistic. Oleh karena itu pengembangan suatu bandara diperlukaan untuk menunjang permintaan demand yang semakin bertambah.

Untuk merencanakan pengembangan bandara Notohadinegoro Jember yaitu menggunakan metode FAA.

Menurut Departemen Perbuhungan, Bandar Udara adalah lapangan terbang yang dipergunakan untuk mendarat dan lepas landas pesawat udara, naik turun penumpang, bongkar muat kargo, serta dilengkapi dengan fasilitas keselamatan penerbangan dan sebagai tempat perpindahan antar moda. Pertumbuhan lalu lintas udara berpengaruh terhadap pesawat terbang dan fasilitas sisi bandara, diantaranya karakteristik serta ukuran pesawat yang direnacakan akan beroperasi pada bandara dan dimensi fasilitas sisi badara meliputi runway, taxiway dan apron.

\section{TINJAUAN PUSTAKA}

\subsection{Beton Bertulang}

Beton adalah suatu campuran yang terdiri dari pasir, kerikil, batu pecah atau agregatagregat lain yang di campur menjadi satu dengan suatu pasta yang terbuat dari semen dan air membentuk suatu masa mirip batuan. 


\section{NAROTAMA JURNAL TEKNIK SIPIL \\ e-ISSN: 2460-3430 \\ VOLUME 3 NOMOR 2 NOVEMBER 2019}

Berdasarkan (SNI 2847-2013), modulus elastisitas beton dapat di tentukan berdasarkan : $\mathrm{Ec}=\mathrm{Wc} 1,5.0,043 \sqrt{\mathrm{fc}^{\prime}}$

Dimana $\mathrm{Wc}=1440-2560 \mathrm{~kg} / \mathrm{m} 3$ untuk beton normal, modulus elastisitas dapat di ambil yaitu $\mathrm{Ec}=4700 \sqrt{\mathrm{fc}^{\prime}}$

Karena sifat dari beton lemah terhadap tarik, maka diberikan baja tulangan untuk menahan tarik. Berdasarkan (SNI 2847-2013), modulus elastisitas Es tulangan non prategang diizinkan untuk diambil sebesar 200,000 Mpa. Kombinasi antara beton dan baja tulangan yang disebut beton bertulang, dimana beton kuat menahan tekan dan baja tulangan untuk menahan tarik.

\subsection{Mutu Beton}

\section{$>$ Mutu Beton fe'}

Beton dengan mutu fc' 25 menyatakan kekuatan tekan minimum adalah $25 \mathrm{MPa}$ pada umur beton 28 hari, dengan mengunakan silinder beton diameter $15 \mathrm{~cm}$ tinggi $30 \mathrm{~cm}$. yang mengacu pada standar SNI 03-2847-2002 yang merujuk pada ACI (American concrete institute)

$\mathrm{MPa}=$ Mega pascal

$1 \mathrm{MPa}=1 \mathrm{~N} / \mathrm{mm}^{2}=10 \mathrm{Kg} / \mathrm{cm}^{2}$

$>$ Mutu Beton Karakteristik

Beton mutu dengan K-250 menyatakan kekuatan tekan karakteristik minimum adalah $250 \mathrm{Kg} / \mathrm{cm}^{2}$ pada umur beton 28 hari, dengan menggunakan kubus beton berukuran $15 \times 15 \times 15 \mathrm{~cm}$. yang mengacu pada PBI 71 yang merujuk pada standar eropa lama.

\subsection{Preliminary Design}

\section{$>$ Perhitungan Dimensi Balok}

Sesuai dengan SNI 2847:2013 pasal 9.5.2.2 maka untuk perhitungan struktur balok menggunakan rumus :

$$
\begin{aligned}
& \mathrm{h}=\frac{1}{8} L \mathrm{~s} / \mathrm{d} \frac{1}{21} L \\
& d=\sqrt[3]{\frac{2 M u}{\varnothing f c^{\prime} \omega(1-0.59 \omega)}} \\
& \omega=0.425 \beta_{1}\left(\frac{600}{600+\mathrm{f}_{\mathrm{y}}}\right) \\
& \mathrm{h} \approx \mathrm{d}+65 \mathrm{~mm}
\end{aligned}
$$

\section{$>$ Perhitungan Dimensi Kolom}

Perhitungan kolom dilakukan sesuai perhitungan beban mati dan beban hidup yang bekerja di sekitar lokasi kolom yang di tinjau.

Berat total :

$$
\mathrm{W}=1,2 \mathrm{DL}+1,6 \mathrm{LL}
$$




\section{NAROTAMA JURNAL TEKNIK SIPIL \\ e-ISSN: 2460-3430 \\ VOLUME 3 NOMOR 2 NOVEMBER 2019}

Selanjutnya dihitung dimensi kolom menggunakan rumus,

\section{$>$ Perhitungan Dimensi Plat}

$$
\begin{gathered}
A g \geq \frac{P_{n}}{0.45\left(f c^{\prime}+f y \cdot \rho_{t}\right)} \Rightarrow \text { Untuk Kolom Persegi } \\
b \approx h: \sqrt{(A g)} \\
A g \geq \frac{P_{n}}{0.55\left(f c^{\prime}+f y \rho_{t}\right)} \Rightarrow \text { Untuk Kolom Bulat } \\
\qquad D=\sqrt{\frac{4 A_{g}}{\pi}}
\end{gathered}
$$

Tebal pelat minimum dengan balok yang menghubungkan tumpuan pada semua sisinya harus memenuhi ketentuan berikut:

(a) Untuk $\alpha_{m}$ yang sama atau lebih kecil dari 0,2 , harus menggunakan persyaratan sesuai SNI 2847:2013 pasal9.5.3.2

(b) Untuk am lebih besar dari 0,2 tapi tidak lebih dari 2,0, h tidak boleh kurang dari :

$$
h=\frac{\ell_{n}\left(0.8+\frac{f_{y}}{1500}\right)}{36+5 . \beta\left(\alpha_{m}-0.2\right)} \quad \ldots \ldots \ldots \ldots \ldots . . . .1 .
$$

dan tidak boleh kurang dari $125 \mathrm{~mm}$.

(c) Untuk am lebih besar dari 0.2 tetapi tidak lebih dari 2, ketebalan plat minimum harus memenuhi :

$$
h=\frac{\ell_{n}\left(0.8+\frac{f y}{1500}\right)}{36+9 . \beta} \ldots \ldots \ldots \ldots . . . .2 .
$$

dan tidak boleh kurang dari $90 \mathrm{~mm}$.

\subsection{Rencana Anggaran Biaya}

Anggaran biaya merupakan harga dari bangunan yang dihitung dengan teliti, cermat dan memenuhi syarat. Anggaran biaya pada bangunan yang sama akan berbeda-beda di lain daerah, disebabkan karena perbedaan harga bahan dan upah tenaga kerja.

\subsubsection{Jenis-jenis Anggaran Biaya}

Dalam menyusun anggaran biaya dapat di lakukan dengan 2 cara yaitu sebagai berikut:

1. Anggaran Biaya Kasar (taksiran)

2. Anggaran Biaya Teliti

\subsubsection{Hal Pokok Dalam Menghitung Biaya}

Perhitungan anggaran biaya biasanya terdiri dari 4 hal pokok, Yaitu:

1. Menghitung banyaknya bahan yang dipakai dan hargannya. bahan-bahan Menghitung jam kerja buruh ( jumlah dan harga) yang di perlukan biasanya taksiran ini disusun dari perkiraan jumlah tukang kayu, tukang batu dan kuli yang di pakai memeriksa bahwa biaya jam ini tidak melewati perkiraannya (A.D Austen dan R.H neale, 1984)

2. Menghitung jenis dan banyaknya peralatan

Ini merupakan bahan yang dibutuhkan selama pembangunan, sepertin pengaduk beton, cangkul, sekrop, ember dan lain-lain. Yang termasuk dalam alat-alat yang diperlukan dalam pekerjaan konstruksi aadalah :

a. mesin-mesin 


\section{NAROTAMA JURNAL TEKNIK SIPIL \\ e-ISSN: 2460-3430 \\ VOLUME 3 NOMOR 2 NOVEMBER 2019}

b. alat-alat tangan

satuan biaya peralatan didasarkan atas waktu penyelesaian pekerjaan atau hasil yang dikerjakan. (manajemen Proyek Konstruksi, Wulfran I ervianto, 2002)

3. Menghitung biaya-biaya yang tak terduga perlu diadakan

Berapa besarnya tambahan biaya yang di perlukan untuk menghadapi keadaan tak terduga seperti itu terggantung dalam berbagai faktor. Satu-satunya petunjuk yang dapat digunakan untuk menentukan berapa tambahan biaya untuk menghadapi keadaan tak terduga pada suatu pekerjaan yang dikerjakan ialah prestasi pada pekerjaanpekerjaan sebelumnya. ( Denis lock, 1990)

\subsubsection{Tahap-tahap Penyusunan RAB}

Dalam penyusunan rencana anggaran biaya terdiri dari beberapatahapan, yaitu:

1. Bill of quantity (BQ)

Bill of quantity adalah perhitungan jumlah kuantitas pekerjaan dalm satuan pekerjaan. Cara menghitung kuantitas pekerjaan tergantung dari pekerjaan itu sendiri, karena setiap item pekerjaan perhitungannya tidak sama.

2. Analisa biaya konstruksi

analisa perkembangan BOW ditinjau dari perkembangan industi konstruksi saat ini

3. Harga satuan pekerjaan (HSP)

Harga satuan pekerjaan adalah jumlah biaya yang meliputi harga bahan, upah tenaga kerja dan sewa alat yang harus dikeluarkan untuk melakukan suatu pekerjaan dalam satu saatuan tertentu yang dihasilkan dari analisis. Harga satu satuan bahan dan upah kerja di setiap daerah yang berbeda-beda.

4. Rencana anggaran biaya (RAB)

Rencana anggaran biaya adalah perhitungan besarnya suatu biaya yang harus dikeluarkan untuk bahan, upah tenaga kerja. secara umum dapat disimpulkan sebagai berikut:

$\mathrm{RAB}=\sum($ volume $\mathrm{x}$ HSP $)$

5. Rekapitulasi

Rekapitulasi adalah menjumlahkan rencana anggaran biaya per-item pekerjaan, sehingga di dapat jumlah total biaya pembangunan. 


\section{NAROTAMA JURNAL TEKNIK SIPIL \\ e-ISSN: 2460-3430 \\ VOLUME 3 NOMOR 2 NOVEMBER 2019}

\section{METODE PENELITIAN}

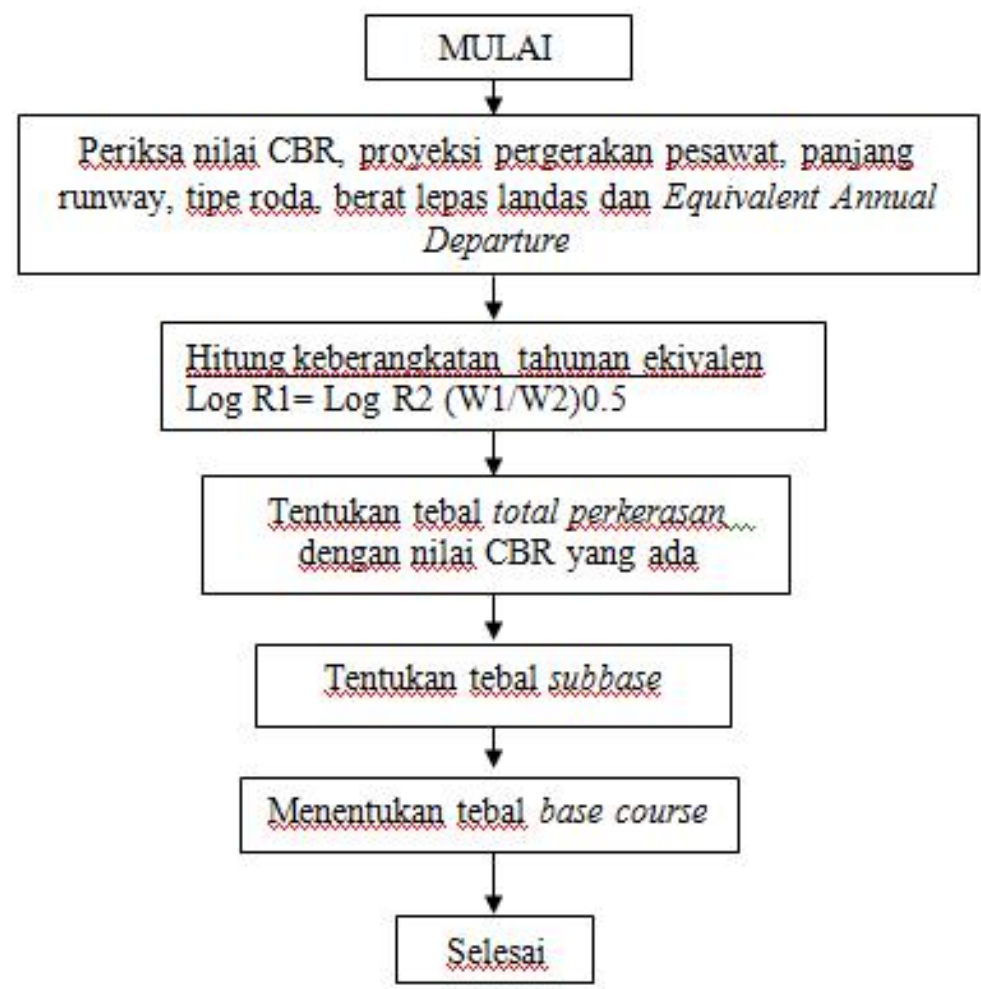

Gambar 1. Diagram Alur Penelitian

\section{ANALISIS DAN PEMBAHASAN}

Proyeksi Pergerakan Pesawat Tahunan

$\mathrm{Rn}=\operatorname{Ro}(1+\mathrm{i})^{\mathrm{n}}$

Dimana:

Ro : data pergerakan pesawat data tahun terakhir

i : prosentase pertumbuhan pergerakan pesawat setiap tahun

$\mathrm{n} \quad$ : jumlah tahun rencana

Tabel 1. proyeksi pergerakan pesawat tahunan

\begin{tabular}{|l|l|l|l|}
\hline No & Jenis Pesawat & $\begin{array}{l}\text { Pergerakan } \\
\text { Pesawat }\end{array}$ & Rn \\
\hline 1 & ATR 72-500 & 1.046 & 138.962 \\
\hline
\end{tabular}




\section{NAROTAMA JURNAL TEKNIK SIPIL \\ e-ISSN: 2460-3430 \\ VOLUME 3 NOMOR 2 NOVEMBER 2019}

\section{b. Panjang Runway}

Data kondisi lapangan yang dibutuhkan untuk perencanaan sebagai berikut :

Elevasi

$$
\begin{aligned}
& =264 \text { feet }=80,4 \mathrm{~m} \\
& =32{ }^{\circ} \mathrm{C} \\
& = \pm 2 \%
\end{aligned}
$$

Temperature Referensi $\quad=32{ }^{\circ} \mathrm{C}$

Slope

Panjang Runway terkoreksi adalah ARFL pesawat kritis yang dikoreksi terhadap elevasi, temperature, dan slope.

1. Koreksi terhadap temperature $(\mathrm{Ft})$

$$
F t=1+0,01(T-(15-0,0065 h)
$$

Dimana:

$\mathrm{h}=$ aerodrome elevasi

$\mathrm{T}=$ temperature referensi

Jadi, $F t=1+0,01(T-(15-0,0065 h)$

$$
\begin{aligned}
& =1+0,01(32-(15-0,0065 \times 80,4) \\
& F t=1.1752
\end{aligned}
$$

2. Koreksi terhadap elevasi $(\mathrm{Fe})$

$$
\begin{aligned}
F e & =1+7 \% \times \frac{h}{300} \\
& =1+7 \% \times \frac{80,4}{300} \\
F e & =1,019
\end{aligned}
$$

3. Koreksi terhadap kemiringan lintasan (Fs)

$$
\begin{aligned}
F_{S} & =1+0,1 S \\
& =1+0,1(2) \\
& =1,002
\end{aligned}
$$

Maka panjang landasan pacu atau runway berdasarkan koreksi terhadap elevasi, temperature dan koreksi terhadap kemiringan lintasan adalah:

$$
A R F L=\frac{\text { Lro }}{\text { FexFtxFs }}
$$

Dimana ARFL $=$ Aerodrome Reference Field Lenght

$$
\begin{aligned}
\mathrm{L} \quad=2.750 \mathrm{~m} \\
=\text { Panjang landasan pacu yang dibutuhkan } \\
2750=\frac{\text { Lro }}{0,28676 \times 1,1752 \times 3,1} \\
\text { Lro }=2750 \times 1,019 \times 1,1752 \times 1,002 \\
=3.299,086 \mathrm{~m}
\end{aligned}
$$

Jadi hasil perhitungan diatas didapatkan panjang runway $3.299,086 \mathrm{~m}$ atau $3.299 \mathrm{~m}$. untuk keamanan dapat digunakan panjang runway sepanjang $\mathbf{3 . 3 0 0} \mathbf{~ m}$. 


\section{NAROTAMA JURNAL TEKNIK SIPIL \\ e-ISSN: 2460-3430 \\ VOLUME 3 NOMOR 2 NOVEMBER 2019}

\section{c. Lebar Runway}

Sesuai dengan Aerodrome Reference Code (ARC) yang dikeluarkan oleh ICAO untuk pesawat rencana B747-400ER ARFL lebih besar dari $1.800 \mathrm{~m}$ dan dengan lebar sayap (wingspan) anatara $52-65 \mathrm{~m}$ adalah 4E. maka untuk menentukan lebar runway rencana minimum yang sesuai dengan ICAO dapat dilihat pada table 2.2. Bandara Notohadinegoro direncanakan mempunyai:

- Lebar landasan 45m, lebar total termasuk bahu landasan kurang lebih $60 \mathrm{~m}$ untuk kode D dan E (Wardhani, 1992)

- Lebar bahu landasan 7,5m (dikedua sisi landasan)

\section{d. Menghitung Forecast Annual Departure $\left(\mathbf{R}_{2}\right)$}

Untuk menghitung jumlah tingkat kedatangan tahunan atau Forecast Annual Departure oleh pesawat rencana dapat dilihat pada perhitungan dibawah ini:

$\mathrm{R}_{2}=$ peregerakan pesawat tahunan $\mathrm{x}$ factor konversi roda

Tabel 2.2. forecast annual departure pesawat

\begin{tabular}{|c|c|c|c|c|c|}
\hline No & Jenis Pesawat & $\begin{array}{c}\text { Pergerakan } \\
\text { Pesawat }\end{array}$ & Rn & $\begin{array}{c}\text { Faktor } \\
\text { konversi roda } \\
\text { pendaratan }\end{array}$ & R2 \\
\hline 1 & ATR 72-500 & 1.046 & 138.962 & 1,7 & $236.235,4$ \\
\hline \multicolumn{5}{|c|}{ Pesawat Rencana } & \\
\hline 1 & B 747 - 400 ER & & & \\
\hline
\end{tabular}

\section{e. Menghitung Beban Roda Pesawat}

Karena pesawat rencana menggunakan konfigurasi roda double dual tandem dan pesawat eksisting menggunakan konfigurasi roda dual wheel gear maka factor pengali konversinya adalah 1,7

$\mathrm{W} 1=$ Beban roda (Wheel load) dari pesawat rencana.

$=\operatorname{MTOW} \times 0,95 \times 1 / \mathrm{n}$

$=394.625 \times 0,95 \times 1 / 8$

$=46.861,72 \mathrm{~kg}$

$\mathrm{W} 2=$ Berat roda dari pesawat yang beroperasi

$=22.000 \times 0,95 \times 1 / 4$

$=5.225 \mathrm{~kg}$ 


\section{f. Menghitung Equivalent Annual Departure (R1)}

Untuk menentukan Equivalent Annual Departure terhadap pesawat rencana menggunakan persamaan sebagai berikut:

$$
\log \mathrm{R} 1=(\log \mathrm{R} 2)\left[\frac{W 2}{W 1}\right]^{1 / 2}
$$

1. Pesawat ATR $72-500$

$$
\begin{aligned}
\log R 1 & =(\log 236.235,4)\left(\frac{5.225}{46.861,72}\right) \frac{1}{2} \\
\log R 1 & =1,794 \\
R 1 & =345,770
\end{aligned}
$$

Tabel 2. Annual Departure

\begin{tabular}{|c|c|c|c|c|}
\hline $\begin{array}{c}\text { TIPE } \\
\text { PESAWAT }\end{array}$ & $\begin{array}{c}\text { KELAS } \\
\text { PESAWAT }\end{array}$ & $\begin{array}{c}\text { KONFIGURASI } \\
\text { SUMBU RODA }\end{array}$ & $\begin{array}{c}\text { MTOW } \\
\text { (Kg) }\end{array}$ & $\begin{array}{c}\text { ANNUAL } \\
\text { DEPARTUERE }\end{array}$ \\
\hline ATR 72-500 & C & Dual Wheel & 22.000 & 138.962 \\
\hline \multicolumn{5}{|c|}{ PESAWAT RENCANA } \\
\hline $\begin{array}{l}\text { Boeing 747- } \\
\text { 400ER }\end{array}$ & E & $\begin{array}{c}\text { Double Dual } \\
\text { Tandem }\end{array}$ & 394.625 & $\mathbf{3 4 6}$ \\
\hline
\end{tabular}

a. Dari perhitungan Equivalent Annual Departure (R1) diatas diperoleh hasil untuk pesawat rencana adalah 346 sebagai nilai Annual Departure

Mengacu pada perhitungan diatas, nilai R1, CBR Subgrade dan MTOW pesawat rencana kemudian diplot pada kurva rencana perkerasan flexible untuk pesawat B 747 


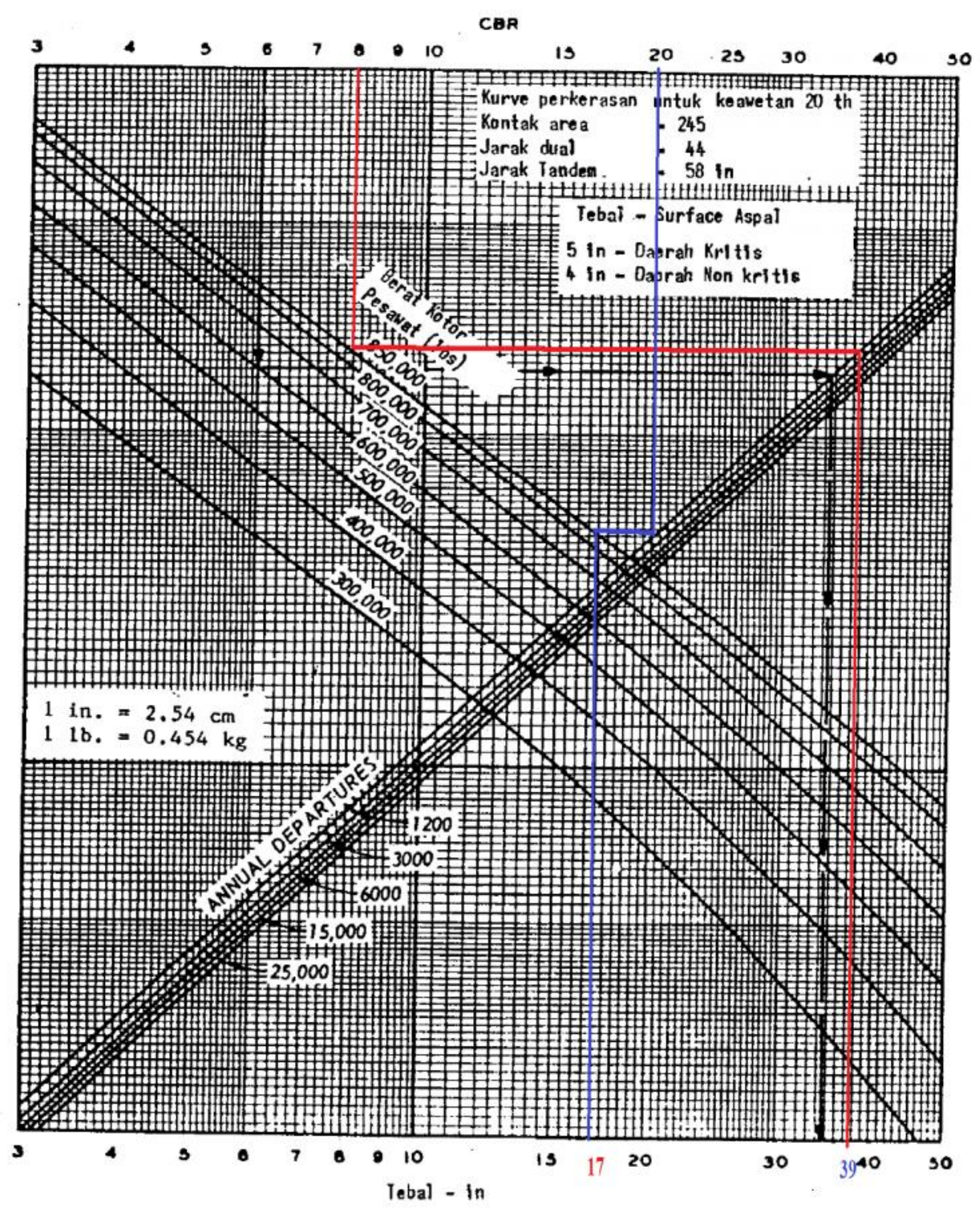

Gambar 2. Kurva Perencanaan Tebal Perkerasan Untuk Pesawat Rencana B 747

Dari gambar 2 diatas maka diperoleh:

a. Tebal total perkerasan adalah 39 inch $=99,06 \mathrm{~cm}=99 \mathrm{~cm}$

b. Ketebalan surface dan base course diatas lapisan subbase dengan CBR $20 \%$ adalah 17 inch atau $43,18 \mathrm{~cm}=43$

Tebal subbase adalah $99-43=56 \mathrm{~cm}$ 


\section{NAROTAMA JURNAL TEKNIK SIPIL \\ e-ISSN: 2460-3430 \\ VOLUME 3 NOMOR 2 NOVEMBER 2019}

c. Tebal surface untuk daerah kritis 5 inch atau $12,7 \mathrm{~cm}=13 \mathrm{~cm}$

d. Tebal base course $43-13=30 \mathrm{~cm}=30 \mathrm{~cm}$

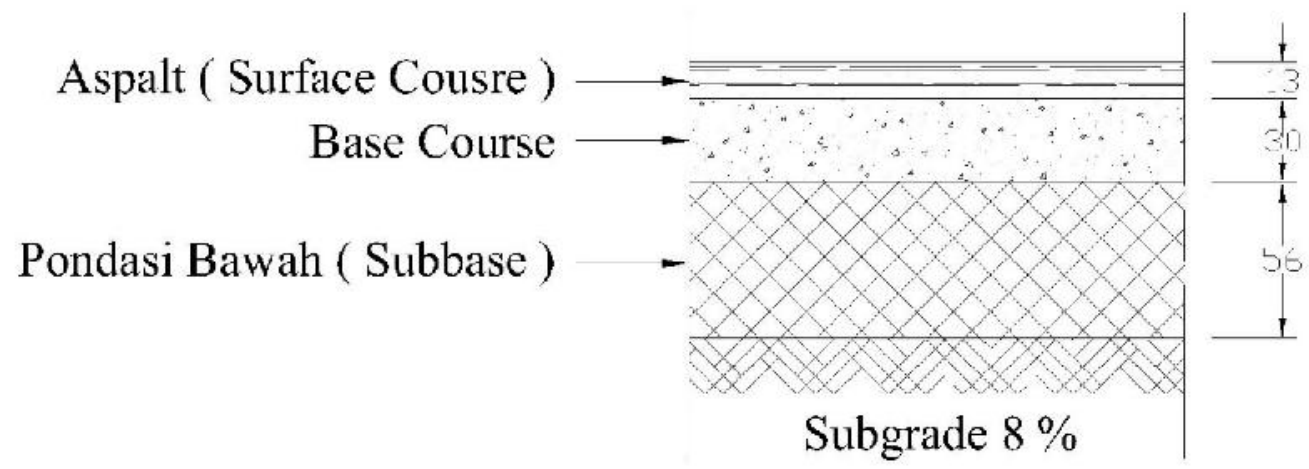

Gambar 3. Perencanaan Tebal Total Perekerasan Lentur

\section{KESIMPULAN} berikut:

Dari pembahasan pada bab sebelumnya, maka dapat ditarik kesimpulan sebagai

a. Kebutuhan panjang runway Bandar Udara Notohadinegoro Jember untuk 20 tahun mendatang setelah dihitung dengan metode FAA yang semula panjangnya $1.645 \mathrm{~m}$ menjadi $3.300 \mathrm{~m}$. Jadi ada penambahan panjang sepanjang $1.655 \mathrm{~m}$.

b. Tebal total perkerasan lentur pada runway untuk panjang dan lebar Bandar Udara Notohadinegoro Jember adalah $99 \mathrm{~cm}$ dengan:

- $\quad$ CBR tanah 8\%

- Lapisan subbase minimum $56 \mathrm{~cm}$

- $\quad$ Lapisan base coarse minimum $30 \mathrm{~cm}$

- Lapisan surface minimum $13 \mathrm{~cm}$

\section{DAFTAR PUSTAKA}

1. Advisory Circular (AC) No. 150_5320_6d (2009). Airport Pavement Design and Elevation.

2. Advisory Circular (AC) No. 150_5320_6E (2009). Airport Pavement Design and Elevation.

3. Boeing Commercial Airplane Group. 747 Airplane Charateristics for Airport Planning. Boeing Corporation. Seattle.

4. Dinas Perhubungan. (2018). Informasi Data Bandar Udara. Bandar Udara Notohadinegoro Jember

5. Haronjeff, Robert, Francis X. McKelvey. (2010). Planning and Design of Airport. 5th.ed

6. Heru Basuki.1986. Merancang, Merencana Lapangan Terbang. Alumni: Bandung 